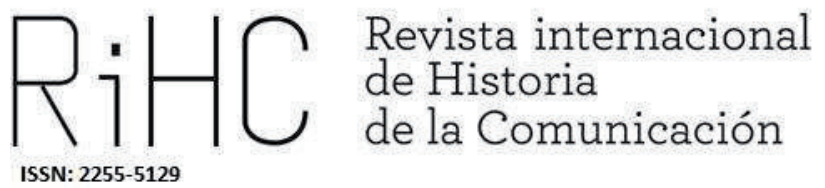

\title{
HISTORIA Y PRESENTE DE LAS CREADORAS AUDIOVISUALES ANDALUZAS: EL CASO DE OLIVA ACOSTA
}

History and present of Andalusian women audiovisual creators: teh case of Oliva Acosta

DOI: http://dx.doi.org/10.12795/RiCH.2021.i16.11

Recibido: 30-3-2021

Aceptado: 26-5-2021

Publicado: 30-5-2021

José Luis Torres-Martín

Universidad de Málaga, España

jltorres@uma.es

ORCID (1) https://orcid.org/0000-0001-6556-1560

Andrea Castro-Martínez

Universidad de Málaga, España

andreacastro@uma.es

ORCID (D) https://orcid.org/0000-0002-2775-625X 
Resumen: Las mujeres han desempeñado históricamente un papel subalterno en el mundo audiovisual, especialmente detrás de las cámaras. La escasez de creadoras audiovisuales se hace más acuciante en Andalucía, región tradicionalmente alejada de los focos de producción de la industria española. La Transición trajo aparejada una incorporación paulatina de las mujeres al sector y prueba de ello es Oliva Acosta. La gaditana ha desarrollado su labor desde los primeros años 90, en los que empezó ideando y dirigiendo documentales en TVE, hasta la creación de su propia productora, pasando por Las constituyentes (2011), su largometraje más premiado. Acosta ha sido, además, responsable de comunicación en Asuntos de lgualdad de la ONU y es miembro de AAMMA. A través de la revisión documental y de una entrevista en profundidad, este estudio de caso indaga en la relevancia histórica de su figura en el audiovisual andaluz y español, así como en su trayectoria profesional, filmografía y rutinas productivas. Los resultados muestran una vida y obra marcadas profundamente por las perspectivas social y de género, con especial interés por la recuperación de la memoria oral de las mujeres y por la incorporación femenina a los puestos técnicos y directivos de la industria audiovisual.

Palabras clave: mujeres, igualdad, audiovisual, documental, Andalucía.

\begin{abstract}
Women have historically played a subordinate role in the audiovisual world, especially behind the camera. The shortage of female audiovisual creators is even more acute in Andalusia, a region traditionally far from the production centres of the Spanish industry. The Transition brought with it a gradual incorporation of women into the sector and proof of this is Oliva Acosta. The Cadiz-born filmmaker has developed her work from the early 1990s, when she began devising and directing documentaries for TVE, to the creation of her own production company, including Las constituyentes (2011), her most awarded feature film. Acosta has also been in charge of communications for Equality Affairs at the UN and is a member of AAMMA. Through a documentary review and an in-depth interview, this case study explores the historical relevance of her figure in Andalusian and Spanish audiovisuals, as well as her professional career, filmography and production routines. The results show a life and work deeply marked by social and gender perspectives, with special interest in the recovery of women's oral memory and the incorporation of women into technical and managerial positions in the audiovisual industry.
\end{abstract}

Keywords: women, equality, audiovisual, documentary, Andalusia.

\title{
Introducción
}

En pleno siglo XXI, la industria audiovisual continúa siendo un territorio masculinizado, tanto delante de la cámara como tras ella. Más allá de oficios tradicionalmente desempeñados por mujeres, como los de script, maquillaje o peluquería, las responsabilidades de dirección, producción y guion de proyectos y la inmensa mayoría de puestos técnicos son habitualmente ocupados por hombres. Todo ello a pesar de la legislación aprobada en las últimas décadas, tanto a nivel estatal -Ley Orgánica para la igualdad efectiva de mujeres y hombres (LO 3/2007, de 22 de marzo), Ley de Comunicación Audiovisual ( $\mathrm{7} / 2010$, de 31 de marzo), Real Decreto que modifica la Ley 
del Cine (RD 1090/2020, de 9 de diciembre)- como andaluz -Ley de creación del Consejo Audiovisual de Andalucía (L 1/2004, de 17 de diciembre), Ley audiovisual de Andalucía ( $L$ 10/2018, de 9 de octubre)-, en la que se pone especial énfasis en la igualdad de oportunidades y de representación entre mujeres y hombres dentro del sector audiovisual.

Las mujeres han desempeñado históricamente un papel subalterno en el mundo audiovisual, especialmente detrás de las cámaras. En nuestro país, concretamente, los nombres de mujeres cineastas prácticamente se reducen a los de Elena Jordi, Musidora, Helena Cortesina y Rosario Pi antes de la Guerra Civil, y a los de Ana Mariscal y Margarita Alexandre durante la dictadura franquista (Zurian, 2015; Barrera, 2019; Vera Balanza y Núñez Domínguez, 2020), así como a la labor pionera de realizadoras como Clara Ronay y Mari Carmen Blanco (Cascajosa Virino, 2015). La escasez de creadoras audiovisuales se hace más acuciante en Andalucía, región tradicionalmente alejada de los focos de producción de la industria española. La Transición Democrática trajo aparejada una incorporación paulatina de las mujeres al sector y prueba de ello es Oliva Acosta, por lo que esta investigación se centra en indagar en su trayectoria.

La presencia de mujeres profesionales ha aumentado en las últimas décadas (Cascajosa Virino y Martínez Pérez, 2016); sin embargo, sigue siendo mucho menor que la masculina, una diferencia que se incrementa cuando se trata de puestos de poder dentro de la industria (Smith, Choueiti y Pieper, 2014; Prommer y Loist, 2015; Eurimages, 2020; Women in Film Los Ángeles, 2020; Swedish Film Institute, 2021).

Los medios de comunicación, el cine y la televisión han perpetuado los estereotipos y roles de género (Ballesteros, 2011; Lozano, 2020), ya que su transmisión a través de la creación audiovisual está relacionada con la prevalencia de la perspectiva masculina (Bartolomé, 2017). Eso se debe a que tiene una gran influencia sobre las temáticas abordadas en las piezas y en su tratamiento, así como en la construcción de los personajes femeninos (Martínez-Collado y Navarrete, 2011). Esta práctica no sólo se da en la ficción, sino que también se reproduce en formatos informativos (Cabrera, Flores y Mata, 2012). En palabras de Micaela Navarro, quien fuese consejera andaluza de Igualdad y Bienestar Social, "Ios medios audiovisuales son unos importantes agentes de socialización en nuestra época y tienen una gran responsabilidad en la configuración de la imagen pública de las mujeres y en la configuración de los géneros" (Fundación Audiovisual de Andalucía, 2009a, p. 42).

En España, la presencia masculina es también mayoritaria en los medios de comunicación, donde existe sexismo mediático derivado de las discriminaciones que sufren las mujeres periodistas y que afecta a los relatos informativos en cuanto a su calidad y carácter inclusivo (Instituto Andaluz de la Mujer, 2020). Así, como el resto de mujeres comunicadoras, las periodistas se enfrentan a barreras de género en su desarrollo profesional (Bañón, 2021). 
Algo similar ocurre en otras profesiones relacionadas con el sector audiovisual, como la animación, que está masculinizada y segregada vertical y horizontalmente. Pese al crecimiento cuantitativo de la presencia femenina en el género, donde "las mujeres representan un $32 \%$ de profesionales en cortometrajes y un $28 \%$ en los largometrajes" (MIA, 2020, p. 94), es evidente el escaso liderazgo femenino en los proyectos, una mayor presencia en cargos vinculados a roles de género y una menor representatividad en pantalla, donde únicamente suponen el $29 \%$ de los personajes hablantes (MIA, 2020).

Tradicionalmente, en el audiovisual los hombres se han encargado de la dirección técnica y artística de los proyectos (Cruzado, 2006; Arranz et al, 2008), pero cuando las mujeres ocupan los puestos como directoras y guionistas aportan nuevas formas de ver el mundo y de contar historias (Ruffinelli, 2014; Weitz, 2016) distintas a las de sus homólogos masculinos. La presencia de las mujeres en el rol de directoras permite traducir el "discurso cinematográfico tradicional a un nuevo lenguaje que ha permanecido silenciado por la maquinaria productiva" (Prado, 1998, p. 76). Además, en los casos en que las mujeres ocupan posiciones de poder en la industria fomentan la incorporación de otras mujeres a los proyectos (Higueras-Ruiz, 2019).

No obstante, en su análisis sobre las películas comerciales españolas estrenadas entre 2001 y 2016, Bernárdez-Rodal y Padilla-Castillo (2018) determinaron, por un lado, que la representación de las mujeres perpetúa los roles de género al presentarlas como acompañantes, ligadas a acciones de cuidados y mediación familiar, y, por otro, que el volumen de mujeres cineastas es muy reducido:

no encontramos película dirigida por una mujer, que haya superado los 10 millones de euros de recaudación, en el periodo estudiado de tres lustros. Para encontrar la primera directora, María Ripoll, hay que descender la franja de recaudación de los 10 millones, hasta el puesto 37 de 100. Por detrás, sólo hay otro título dirigido por una mujer, Te doy mis ojos. (Bernárdez-Rodal, y PadillaCastillo, 2018, p. 1.257).

De otro estudio sobre el cine español dirigido por mujeres entre 1989 y 2009 (Núñez Domínguez, 2010a, pp. 131-132), se desprenden las siguientes conclusiones:

- Hay 122 películas dirigidas por 56 mujeres, lo que supone como máximo un $7 \%$ del cine español estrenado.

- A pesar de las dificultades han conseguido reconocimiento internacional.

- La mayor parte logra financiación para un único proyecto y hay muy pocas cineastas que superan los tres estrenos.

- En gran parte se trata de producción propia o de bajo presupuesto.

- Emplean géneros cinematográficos variados, aunque destaca el drama. También la comedia con una visión irónica y crítica, y en los últimos años el documental.

- Sus motivaciones son sociales además de comerciales. 
- Conceden liderazgo argumental a personajes femeninos, contra la tendencia del cine español.

A las dificultades propias del sector se suman otras derivadas de los sesgos de género, como las responsabilidades familiares. La conciliación es una fuente de estrés para las directivas del audiovisual que, en numerosas ocasiones, dificulta o directamente impide su desarrollo profesional, ya que hay "muchas mujeres que, aun teniendo cualidades técnicas e ideas creativas, postergan sus proyectos audiovisuales o (simplemente) no los acometen" (Núñez Domínguez, 2014, pp. 88-89). En un trabajo sobre la producción cinematográfica andaluza desarrollado por Ocón Aburto y Núñez Domínguez (2020) se indica que, respecto a la actividad profesional, el empleo del tiempo es similar entre hombres y mujeres, pero que ellas dedican mucho más al ámbito doméstico obstaculizando su ascenso profesional.

A las barreras que deben enfrentar las mujeres para hacer cine en España se suman las propias de ejercer en zonas alejadas de los grandes centros de producción, como ocurre en Andalucía, puesto que "a poco cine, pocos realizadores o guionistas y, por supuesto, menos mujeres en el medio" (Guarinos, 1999a, p. 133). Las prácticas comunicativas periféricas ponen en valor otras perspectivas y habitualmente dan voz a temáticas y a colectivos infrarrepresentados en los discursos hegemónicos (Torres-Martín y CastroMartínez, 2021). En el caso andaluz, la industria audiovisual se caracteriza por la temporalidad, la gran atomización y la concentración en Sevilla y Málaga, y está protagonizada por hombres de entre 30 y 40 años, con alta formación y fuerte vocación (Fundación Audiovisual de Andalucía, 2009, pp. 227-228). Por su parte, las mujeres profesionales sienten que "a los directivos se les presuponen ciertas capacidades que las directivas tienen que demostrar continuamente. No se aplica la presunción de inteligencia (racional y emocional) a las mujeres directivas y sí a sus colegas" (Núñez Domínguez, 2010b, p. 2).

Hasta final de los años 90, prácticamente las únicas directoras andaluzas presentes en las bibliografías sobre cine andaluz eran Pilar Távora y Chus Gutiérrez, ya que el resto de las mujeres eran en su mayoría cortometrajistas -Inmaculada Hoces, Carmen Sánchez Pérez, Isabel Hernández Sular, Leticia Alegre, Victoria Fonseca y Carmen Flores- o desempeñaban otras funciones: Maruja Soriano y Carmen Frías (montadoras), Victoria Fonseca, Julia de la Rosa y Milagros Viñas (ayudantes de dirección), Rosa Fernández y Montse Roura (productoras ejecutivas) y la directora artística Rosa Cossío (Guarinos, 1999a, pp. 134-135). Aunque también existían figuras como Pepa Álvarez, productora, directora de documentales, cortometrajista y guionista (Guarinos, 1999b). Según el estudio elaborado en 2015 sobre la situación de las mujeres en el audiovisual andaluz (Silva, 2015) únicamente el $27,8 \%$ de los trabajadores del sector eran mujeres, las únicas tareas ocupadas mayoritariamente por mujeres eran sastra, peluquera y maquilladora, destacando la escasa presencia de directoras, guionistas y realizadoras y el equilibrio en el rol de la ayudantía de producción. 
Nuñez Domínguez y Vera Balanza (2020), en su inventario de directoras y películas argentinas y españolas realizadas entre 2000 y 2010 -donde identifican a 72 directoras y 138 producciones-, destacan la importancia de identificar figuras femeninas en la industria:

la vindicación de su autoría, la tarea de enlace entre las generaciones más veteranas y las realizadoras más jóvenes, constituyen un hecho fundamental, porque dan continuidad y sentido, instituyen modelos de referencia y generan una genealogía propia que saca de la excepcionalidad no solo sus propias trayectorias profesionales, sino la participación de las mujeres en la historia de las cinematografías nacionales y universales (Núñez Domínguez y Vera Balanza, 2020, p. 124).

\section{Metodología}

El objeto de estudio de esta investigación ahonda en la importancia histórica de la figura femenina en el sector audiovisual español a través del estudio del caso (Wimmer y Dominick, 1996) de Oliva Acosta. Con un diseño cualitativo se pretende determinar la relevancia de su papel en la industria. Los objetivos secundarios son:

- profundizar en la evolución de su carrera desde sus inicios.

- identificar su filmografía.

- conocer sus rutinas productivas.

Las herramientas de recolección de información que se han empleado son la entrevista en profundidad (Gaitán y Piñuel, 1998) y la revisión documental (Del Río y Velázquez, 2005), a través de las cuales la investigación desentraña las peculiaridades de la obra de esta protagonista del audiovisual andaluz.

La entrevista en profundidad se ha realizado en marzo de 2021 y se procedió a su transcripción para permitir un análisis pormenorizado de las respuestas. La revisión documental se ocupa de distintos textos escritos y audiovisuales, como son los registros e intervenciones de la creadora en:

- Internet Movie Database (IMDb, 2021)

- La Asociación Andaluza de Mujeres de los Medios Audiovisuales (AAMMA, 2021): información biográfica y filmográfica sobre su producción.

- Participación de Oliva Acosta como moderadora en Women in Focus, sección del Festival de Cine Europeo de Sevilla 2015, de la mesa redonda Sin las mujeres no es cine (Universidad Internacional de Andalucía, 2015, 13 noviembre). 
- Participación de Acosta en un coloquio en Cines Zoco Majadahonda con motivo de Las constituyentes (Cines Zoco Mahadahonda, 2014, 4 de septiembre).

- Entrevistas a Oliva Acosta (Martín, 2013, 31 enero; Gorjón, n.d.; Sardá, 2012, 14 diciembre).

\section{Resultados}

\subsection{Primeros años como comunicadora en la ONU}

Oliva Acosta, nacida en Cádiz en 1960, es periodista, guionista, directora, productora y formadora. No se forma originariamente como una profesional del audiovisual, sino que previamente, en los primeros años de la década de los 90, se dedica a tareas informativas relacionadas con las cuestiones de género como responsable de Comunicación en la División de Asuntos de Igualdad de la Secretaría de la ONU, en su sede central de Nueva York, entre 1994 y 1999: "Me inicio en el audiovisual poco después de la Conferencia de Pekín, en China, Conferencia de las Naciones Unidas por los Derechos de las Mujeres en la que yo trabajé en toda la parte preparatoria dentro del Departamento de Comunicación" (Acosta, comunicación personal, 23 de marzo de 2021).

De este modo, participó en la organización de la IV Conferencia Mundial de la ONU sobre las Mujeres de Pekín en 1995 y en su seguimiento durante los tres años posteriores a su celebración. Durante este periodo, Acosta desarrolló en Naciones Unidas proyectos innovadores consistentes en plataformas online de contenidos digitales sobre la igualdad, como la web WomenWatch. Después de esta etapa coordinó desde Bruselas la Red Internacional de Derechos Humanos de la Mujer, Women's Human Rights Net, una iniciativa que reunía a oenegés de todo el mundo en una única plataforma internacional.

En aquella experiencia descubre el potencial de los nuevos medios digitales: "La demanda de información fue impresionante; yo estuve trabajando en la elaboración de la primera página web de Naciones Unidas. Con un manual comprado en una librería de Manhattan diseñé la primera web, muy rudimentaria, que todavía se puede ver en Internet" (Acosta, comunicación personal, 23 de marzo de 2021). Este trabajo no acaba con la celebración de dicha conferencia, ya que le siguen otros 3 años de trabajo en Nueva York. Continuará vinculada a Naciones Unidas, esta vez como consultora freelance, cuando se traslada a Bruselas. Allí compartirá su actividad con la Women's Human Rights Net, "un grupo de oenegés de todo el mundo que querían seguir ese 
concepto que introduje en la Conferencia de Pekín con el que aunar esfuerzos a través de la web" (Acosta, comunicación personal, 23 de marzo de 2021). Este periodo iniciático representó un crecimiento a todos los niveles:

fue maravilloso, muy intenso, agotador, pero a su vez muy creativo y, sobre todo, riquísimo, ya que estuve trabajando con un equipo de compañeras con una grandísima experiencia a nivel político en el ámbito internacional. Aprendí muchísimo de liderazgo, de feminismo y política, tuve referentes maravillosos que me ayudaron a ser la persona y la profesional que soy hoy en día. Fue un proceso de empoderamiento a todos los niveles, personal y político (Acosta, comunicación personal, 23 de marzo de 2021).

En ese momento es consciente de las potencialidades del audiovisual a la hora de amplificar su mensaje: "rápidamente me di cuenta que, con un poco de esfuerzo más y si recurríamos al audiovisual, podríamos llegar a muchísima más gente" (Acosta, comunicación personal, 23 de marzo de 2021). De esa conclusión surge su primer documental, "Beijing +5. Acciones, no palabras, que fue emitido por Televisión Española en La noche temática a una hora intempestiva, pero que tuvo mucha más repercusión. Esa fue claramente la motivación para abandonar lo anterior y dedicarme a la creación de contenidos audiovisuales" (Acosta, comunicación personal, 23 de marzo de 2021). Su formación autodidacta y la escasez de mujeres dedicadas a los procesos de creación y realización en el audiovisual español de aquellos años no supusieron ningún obstáculo para la autora:

Estaba viviendo en un contexto de feminismos, de redes de mujeres desde el año 93, en la Conferencia de Pekín, con toda la intensidad del trabajo de las oenegés y del entorno de Naciones Unidas, y no lo pensé. Me lancé y estaba rodeada por multitud de referentes de mujeres importantes en la política internacional, pero muy pocos referentes en el ámbito del audiovisual porque no me había formado dentro de ese mundo; soy periodista de profesión y había un techo de cristal, pero éramos muchísimas mujeres las que estábamos trabajando, y concretamente aún más en ese ámbito de Naciones Unidas (Acosta, comunicación personal, 23 de marzo de 2021).

\subsection{Primeros trabajos audiovisuales}

La relación de Oliva Acosta con Documentos TV, el mítico formato de TVE, comienza con su segundo proyecto: "Se lo presenté a Pedro Erquicia -director del programa desde sus inicios- y me acuerdo que me dijo: '¿Ves todo este armario que está lleno de archivos? Todos son proyectos que me llegan. A ver, ¿por qué tengo que hacer el tuyo?'” (Acosta, comunicación personal, 23 de marzo de 2021). Finalmente, esta idea se llevó a cabo bajo el título de Somos lo que comemos, escrita y codirigida por la gaditana. Su nexo de unión 
con Documentos TV no se rompió aquí, sino que, desde productoras externas, se extendió en el tiempo con "Madres invisibles e Infancia rota, documentales que tuvieron mucha repercusión" (Acosta, comunicación personal, 23 de marzo de 2021). Infancia rota se alzó con diversos premios como el del Festival de Televisión de Nueva York, el Intermedia de Plata del Festival de Hamburgo y el Premio Derechos Humanos del Consejo General de la Abogacía. Somos lo que comemos (Documentos TV) fue igualmente nominado al mejor programa de televisión en la Bienal Internacional de Cine Científico de Málaga.

Esta etapa de colaboración con el espacio televisivo es recordada muy positivamente por la autora: "significó una progresión muy interesante, una evolución tanto a nivel personal como profesional: del documental más periodístico al más creativo, donde pudiera contar las historias que me interesaban y así aprovechar toda la dimensión que nos proporciona el audiovisual" (Acosta, comunicación personal, 23 de marzo de 2021).

Estas producciones supusieron un punto de inflexión en la carrera de la creadora:

Eran -los anteriores- documentales muy periodísticos y tenía ganas de ir innovando, de crear cosas nuevas $y$, aprovechando que estaba en el ámbito audiovisual, de hacer un cine documental creativo dentro de lo periodístico. Dentro de Documentos TV algo se podía hacer, pero el programa tenía una impronta muy marcada. En Barcelona, con mi compañera Elena Ortega, surge el primer guion y la propuesta de codirigir junto a ella nuestro primer documental más creativo, Reyita (Acosta, comunicación personal, 23 de marzo de 2021).

\subsection{Olivia Acosta como productora y directora de documentales}

En 2007 crea su propia productora, Olivavá Producciones, en Chiclana (Cádiz), donde se especializará en la creación y producción de contenidos audiovisuales y digitales, los cuales tienen una clara perspectiva social, educativa y de género. La instala en la localidad de donde es originaria su familia, Chiclana. Esta decisión la argumenta así: "Con mi experiencia anterior, tenía clarísimo que se podía trabajar a nivel nacional e internacional teniendo una línea de Internet. Entonces, ¿por qué trabajar desde una urbe? Después de trabajar en Nueva York tenía ganas de estar en contacto con la naturaleza" (Acosta, comunicación personal, 23 de marzo de 2021). Pero a esta necesidad vital se le unía otra motivación más pragmática: "También era una oportunidad porque no había tantas productoras, y menos dirigidas por mujeres, por lo que instalarme en Andalucía desde Cádiz me pareció estratégico y oportuno" (Acosta, comunicación personal, 23 de marzo de 2021). A estas razones hay que añadir un interés por narrar y comunicar desde un punto alejado de los tradicionales focos mediáticos: 
"Ver el mundo desde la periferia, desde la frontera. Estar tan cerca de África te otorga oportunidades" (Acosta, comunicación personal, 23 de marzo de 2021).

Como es lógico por su origen, dentro de ese interés por los temas periféricos destaca el mostrado por la identidad andaluza y, específicamente, por sus mujeres: "Lo andaluz me ha interesado siempre porque la historia de mi familia es andaluza. Aunque mis padres se fueron a trabajar a Madrid y yo me crie allí, me considero gaditana totalmente y tenía mucho interés por estar aquí" (Acosta, comunicación personal, 23 de marzo de 2021). Su primer largometraje, el anteriormente citado Reyita, fue rodado en Cuba en ese mismo año y supuso "la primera historia que contamos sobre la memoria de las mujeres. Es un relato coral donde, a través de todos los testimonios de la familia, reconstruimos los recuerdos de una mujer que había fallecido hace tiempo" (Acosta, comunicación personal, 23 de marzo de 2021). Sin embargo, se encontró con la historia de la protagonista de un modo totalmente fortuito: "Fui por trabajo a un Congreso sobre la Historia de las Mujeres en La Habana y allí me hablaron de esta mujer y de que había un grupo de mujeres feministas clandestino en Cuba. Una historiadora miembro del mismo había escrito la historia de su madre Reyita" (Acosta, comunicación personal, 23 de marzo de 2021). Desde que entró en contacto con la obra, Acosta tomó conciencia de que "había una historia por contar y que era la de muchas mujeres, como mi madre o mi abuela. Mujeres que han significado mucho a través de la ingeniería de lo personal" (Acosta, comunicación personal, 23 de marzo de 2021). Con esta narración pretendía demostrar su relevancia "no solamente en lo personal de su familia, sino también en lo político. Además de que lo personal es político, había una historia de militancia política que ninguno de sus hijos conocía" (Acosta, comunicación personal, 23 de marzo de 2021). Por tanto, y pese al salto al medio cinematográfico, la autora continuaba tratando aquellos temas que serán recurrentes a lo largo de toda su trayectoria:

Desde el principio tenía muy claro que quería reflejar la perspectiva social y de género porque estaba trabajando con un compromiso muy importante desde el feminismo hacía muchísimos años. [...] Mi interés residía en contar las historias que no se estaban contando, historias que, desde mi punto de vista, más hacía falta que se contaran. A mí también me faltaban mis referencias, mi genealogía, y quería bucear en esas historias que yo también necesitaba como mujer y como cineasta para ir construyéndome como persona y como profesional (Acosta, comunicación personal, 23 de marzo de 2021).

Inmersa en su nueva faceta como productora, la creadora afronta el que, hasta el momento, es su documental más laureado, Las constituyentes: "me invitan a un concurso para hacer un corto sobre las constituyentes. Se celebraba el centenario de La Pepa, la Constitución de 1812, y el Consorcio del Bicentenario quería hacer un homenaje a esas diputadas" (Acosta, comunicación personal, 23 de marzo de 2021). El proyecto 
audiovisual está basado en una obra de investigación sobre aquellas mujeres pioneras en la política española durante La Transición:

Todo viene de María Teresa Fernández de la Vega, que era vicepresidenta del gobierno y directora del Consorcio. Ella encarga este estudio primero a la Red de Mujeres Constitucionalistas, que dirige Julia Sevilla, que cristaliza con una publicación muy importante sobre las mujeres parlamentarias de la legislatura constituyente, que es la biblia donde yo bebo para construir un largometraje (Acosta, comunicación personal, 23 de marzo de 2021).

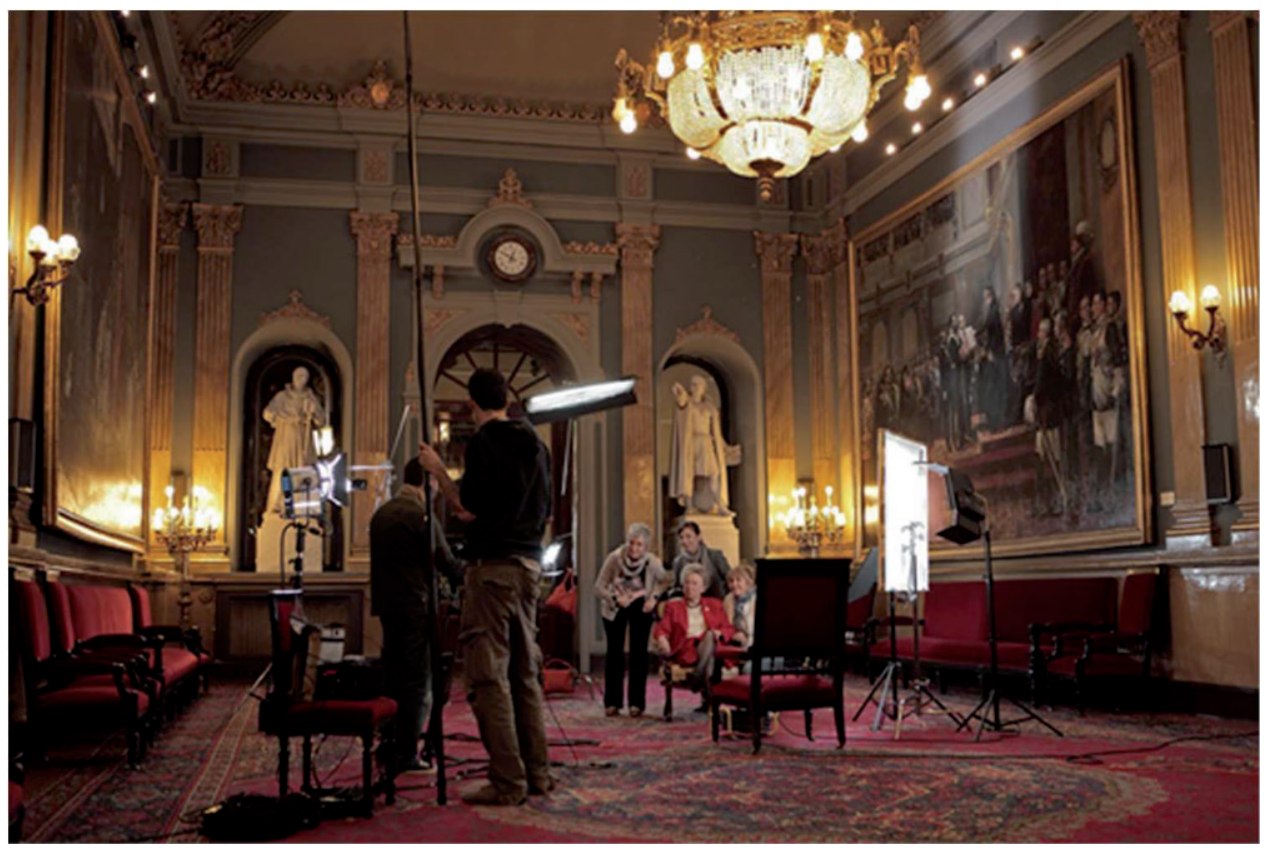

Imagen 1. Rodaje de Las Constituyentes. Fuente: Oliva Acosta

De la dirección del corto original se tiene que hacer cargo Áurea Fernández por enfermedad de Oliva Acosta. Sin embargo, la autora tenía claro que el tema tenía suficiente consistencia para un largometraje. Los testimonios de las protagonistas durante el rodaje dejan una profunda huella en la directora:

No me sorprenden los testimonios de estas mujeres, pero me marcan profundamente porque tienen una dimensión política que yo no conocía y que también había sido sepultada por el tiempo. Mi actitud al entrevistarlas fue la de tener delante a Clara Campoamor, cuyo testimonio se podría haber filmado en la época, pero que no existe. Mi motivación se basó en que esto no podía volver a ocurrir (Acosta, comunicación personal, 23 de marzo de 2021).

De todo el reconocimiento que obtuvo esta película documental, Acosta se queda con lo siguiente: "La respuesta del público y de la crítica me llenó de satisfacción y me ha dado los mejores años de mi vida profesional, así como el orgullo de haber contado una 
historia importante para nuestro país" (Acosta, comunicación personal, 23 de marzo de 2021).

\subsection{Proyectos como formadora y compromiso feminista desde el audiovisual}

Olivavá Producciones también ha orientado su trabajo hacia el ámbito formativo, llevando a cabo acciones en base a los materiales audiovisuales que produce sobre igualdad y valores ciudadanos en centros educativos de Andalucía. Esta nueva faceta como profesional audiovisual de Oliva Acosta se inicia a partir de la repercusión obtenida por Las constituyentes: "A partir de esta experiencia en el trabajo sobre la perspectiva de género, me empiezan a pedir que participe en charlas y me introduzco en el ámbito de la formación. Empiezan a solicitarme que monte algún tipo de taller para transmitir estas ideas a las nuevas generaciones" (Acosta, comunicación personal, 23 de marzo de 2021). El desarrollo de este proyecto se ha llevado a cabo en los siguientes términos: "Ahí es donde empiezo a crear el guion de mi formación, tratas de hacerlo de la forma más innovadora y audiovisual posible, y empiezo a llevar este taller sobre rodaje con perspectiva de género a muchísimos lugares de nuestro país" (Acosta, comunicación personal, 23 de marzo de 2021). En este proceso no solo han participado profesionales del audiovisual, sino que se ha creado "un grupo para realizarlo con personas expertas en pedagogía" (Acosta, comunicación personal, 23 de marzo de 2021). Gracias a dicha labor, la gaditana ha descubierto su "vocación de formadora y de comunicadora especializada en trabajar con gente joven. Ellos me han llenado de energía y ha sido una experiencia muy buena" (Acosta, comunicación personal, 23 de marzo de 2021).

Desde 2012 se intensificó su actividad formadora en el ámbito de la participación, la ciudadanía y el empoderamiento en igualdad. Más de cuatro mil asistentes han participado en sus talleres para alumnado, profesorado de institutos y universidades, colectivos de mujeres y de mayores, así como para numerosas administraciones y entidades públicas.

Sin embargo, esta tarea formativa no ha impedido que continúe realizando trabajos de guion, dirección y producción. Entre ellos destaca, en 2014, 25 años abriendo camino:

El caso de 25 años abriendo camino fue un encargo del Instituto Andaluz de la Mujer que realicé con Ana Rosa Diego y desde la AAMMA. Fue una experiencia preciosa investigar en esa rama, en esa red de mujeres que empezaron desde hace ahora 30 años a trabajar en el tema de género en Andalucía, a impulsar todos los programas de igualdad desde la Junta de Andalucía. Conocer a esas mujeres, guardar su legado y su memoria fue el objetivo de ese documental (Acosta, comunicación personal, 23 de marzo de 2021). 
Por tanto, el compromiso feminista de Oliva Acosta se plasma en su trabajo mediante una doble vertiente: en primer lugar, la recuperación de la memoria de todas las mujeres a través de sus testimonios orales. Así lo corrobora con la siguiente afirmación: "la brújula se situó en ese norte que era recuperar mi historia, la historia de las mujeres. [...] Me quedó esa transparente claridad, esa línea muy precisa de trabajo. Lo que quiero es utilizar mi tiempo y mi capacidad para contar lo que no se ha contado" (Acosta, comunicación personal, 23 de marzo de 2021). Este afán por rescatar la oralidad de las mujeres no solo se ha visto en los largometrajes anteriormente citados, sino también en obras más recientes y de menor extensión como Las memorables, mediometraje documental destinado a guardarse como legado de las mujeres mayores de Chiclana junto a un disco con sus canciones de juventud- en el Museo Municipal: "Veía a mi familia y se conocía la historia de los varones, pero no se conocía nada de la genealogía materna, de las mujeres de la familia. [...] Investigué también la historia de mi madre y de las mujeres de esa edad de la localidad en ese documental" (Acosta, comunicación personal, 23 de marzo de 2021).

La segunda vertiente de dicho compromiso se ha fundamentado en el establecimiento de redes de contacto entre las mujeres del sector: la directora es parte de la junta directiva de la Asociación Andaluza de Mujeres de los Medios Audiovisuales (AAMMA), de la ostentó la presidencia durante tres años, y también es miembro de la Academia de las Artes y las Ciencias Cinematográficas de España. "Nunca he abandonado la militancia feminista y, llegado un momento, decidí que mi militancia se desarrollase dentro del sector audiovisual. Por eso, me impliqué muchísimo en la creación de la AAMMA hace más de 7 años y, además, presidí la asociación durante 3 años, en la que ahora sigo como vocal" (Acosta, comunicación personal, 23 de marzo de 2021). Esa militancia se ha extendido al ámbito legislativo: "Me he implicado igualmente en la elaboración de las leyes del cine y del audiovisual en Andalucía, vigilando y aportando mi experiencia para que dichas leyes tuvieran una perspectiva de género, algo que se ha conseguido y de lo que estoy muy satisfecha" (Acosta, comunicación personal, 23 de marzo de 2021). Asimismo, esta visión ha marcado su faceta formadora:

siempre insisto entre los jóvenes que pueden desarrollar sus vocaciones dentro del sector. Tenemos directoras, guionistas, sonidistas, pero aún queda por difundir aquellos empleos menos conocidos para que puedan desarrollarse como profesionales del audiovisual. En cuanto a las mujeres que quieren trabajar en el sector, siempre recomiendo que trabajen en red, que se asocien a las organizaciones que ya existen y que unan sus esfuerzos porque juntas somos más fuertes. Les recomendaría que no se desanimen, que hay espacio y que la sociedad está esperando esas historias, por lo que no podemos dejar de contarlas (Acosta, comunicación personal, 23 de marzo de 2021). 


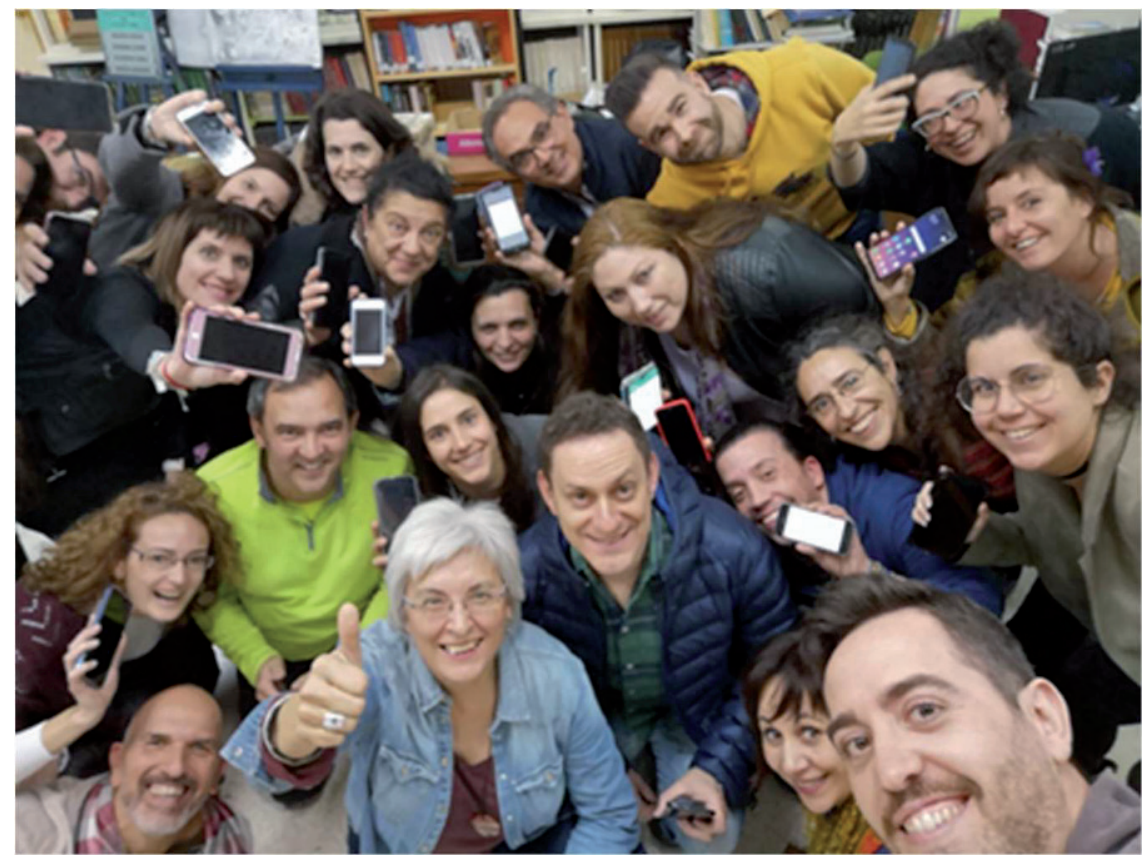

Imagen 2. Curso Rodaje con G: Cre-Acción audiovisual y participación por la igualdad. Fuente: Oliva Acosta.

En cuanto a la presencia femenina en el sector, Acosta reconoce una importante progresión íntimamente ligada al crecimiento del asociacionismo:

Cuando empezamos en la asociación éramos 15, ahora somos 170 . El interés y el aprendizaje de lo que significa el trabajo en red, y ese darnos la mano para ir escalando esta montaña, que a veces es montaña rusa, así como para ir rompiendo ese techo de cristal o de hormigón para que las mujeres puedan estar en los cargos directivos y liderar la creación y la narración de historias en igualdad con los hombres (Acosta, comunicación personal, 23 de marzo de 2021).

Ese asociacionismo ya ha rebasado los límites de nuestra comunidad autónoma: "desde AAMMA hemos establecido una red con otras asociaciones de mujeres en el audiovisual, como las del País Vasco, Cataluña, Valencia y Murcia, así como la Asociación de Animación, por lo que actualmente representamos a más de mil mujeres en el ámbito territorial" (Acosta, comunicación personal, 23 de marzo de 2021). Su objetivo no es otro que el de conseguir una igualdad real en el sector entre hombres y mujeres: "Desde ahí estamos dando batalla para pedir la luna: no solo tener unos puntos por un proyecto dirigido por una mujer para las subvenciones o ayudas a la creación audiovisual, sino que el dinero público se reparta en igualdad entre los varones y las mujeres, lo que representaría una cuota del 50\%" (Acosta, comunicación personal, 23 de marzo de 2021). Sin embargo, la autora observa una evolución dispar a nivel nacional y autonómico: "El ICAA -Instituto de la Cinematografía y de las Artes Audiovisuales- ha recibido esta propuesta, tras el trabajo que había realizado anteriormente CIMA Asociación de Mujeres Cineastas y de Medios Audiovisuales-, con voluntad política. En 
Andalucía este trabajo se está desarrollando más lentamente, pero estamos abriendo camino para conseguir que en 2025 se consiga esa cuota del 50\% de dinero público" (Acosta, comunicación personal, 23 de marzo de 2021).

Por último, con respecto a la representación de las mujeres en los cargos de responsabilidad dentro de la industria audiovisual, la creadora gaditana lo tiene claro: "Las mujeres nos vamos incorporando a las labores de liderazgo dentro del sector, aunque todavía los datos no reflejan las cifras necesarias para estar en situación de igualdad" (Acosta, comunicación personal, 23 de marzo de 2021). Pese a su paulatina incorporación y al aumento considerable del número de mujeres en el sector en los últimos años, son aún pocas las que ocupan puestos de decisión: "Las mujeres están en los cargos intermedios, hay muchas en producción y en realización de documental, pero aún pocas en dirección. En Andalucía todavía son pocas las mujeres que se dedican a la ficción. A este paso, llegaremos a esa igualdad en 2050" (Acosta, comunicación personal, 23 de marzo de 2021). Pero esta realidad no le resta ambición a Oliva Acosta: "Hay que pisar el acelerador, hay que seguir trabajando e impulsando medidas de acción positiva para que las mujeres podamos contar nuestras historias" (Acosta, comunicación personal, 23 de marzo de 2021).

La autora mantiene que, para lograr una presencia equilibrada de las mujeres en la industria y potenciar su visibilidad, es necesaria una sinergia con los hombres, ya que no se contempla como una prioridad ni en los festivales ni en el sector fomentar el espacio para el debate sobre la situación de las mujeres en el audiovisual.

De la misma forma, señala que es precisa una toma de conciencia de la situación de desigualdad y de las dificultades a las que se enfrentan las mujeres en este ámbito laboral, además de replantearse los mensajes audiovisuales que se consumen a través de la televisión y en cine, debido a que conducen a prototipos de mujeres y hombres que distan mucho de ser igualitarios. $Y$ es que recuerda que las mujeres aportan valores diferenciales que quedan ocultos si siempre se representa desde la perspectiva masculina. Un ejemplo claro es su trabajo Las constituyentes, que considera importante porque ayuda a conectar con las ancestras en política, pues no existen discursos audiovisuales que recojan las figuras de mujeres en el poder político. Así, mediante estos documentos se pueden ofrecer modelos de mujeres en el poder político para amueblar el imaginario colectivo de las generaciones presentes y de las pasadas, que también carecen de esos referentes.

\subsection{Filmografía y reconocimientos}

A continuación, se desglosa su filmografía completa: 
$\notin$ Beijing +5 . Acciones, no palabras (1995) rodado en la ONU en Nueva York y emitido en el programa La Noche Temática de Televisión Española.

$\notin$ Somos lo que comemos (2002). Documental para Documentos TV de Televisión Española (TVE-La2) sobre la industria alimentaria. Nominado al mejor programa de TV en la Bienal Internacional de Cine Científico de Málaga.

$\notin$ Infancia rota (2005), pieza documental para el programa Documentos TV de Televisión Española (TVE-La2) que aborda el abuso sexual a menores. Obtuvo diversos premios como el Premio Derechos Humanos (2005), el Globo de Plata en el World Media Festival (2006), el Premio del Festival de Nueva York al mejor reportaje de investigación, la Medalla de Bronce en el Festival Internacional de Nueva York (2007).

$\notin$ También ha trabajado en otros Documentos TV como Mi vida por 1000 euros, Hombres o Mujer quiere a Mujer. Madres Invisibles.

$\notin$ Reyita (2007): largometraje documental sobre la revolución cubana desde la mirada de una mujer anónima, se rodó en La Habana y Santiago y se estrenó en el Festival Internacional del Nuevo Cine Latinoamericano de La Habana. Posteriormente participó en numerosos festivales nacionales e internacionales, estrenándose en cines en España en 2008.

$\notin$ Las constituyentes (2011): directora, guionista y productora. El largometraje documental ha sido calificado por el Ministerio de Cultura como "película especialmente recomendada para la promoción de la igualdad de género" y fue premio Meridiana 2011 de la Junta de Andalucía, entre otros importantes reconocimientos. La Comisión de Igualdad del Congreso de los Diputados recomendó que la película llegase al público más amplio posible, y en especial al mayor número posible de centros de enseñanza y centros académicos españoles.

$\notin 25$ años abriendo caminos (2014): corto documental como homenaje al trabajo de tantas mujeres que a lo largo de los 25 años de vida del Instituto Andaluz de la Mujer han luchado por los derechos, oportunidades y libertades de todas las andaluzas.

$\notin$ La murga, una ópera popular (2014): largometraje documental en coproducción sobre el mundo del carnaval y la conexión entre las ciudades de Cádiz, Montevideo y Tenerife.

$\notin$ Las Memorables (2019): proyecto creado y dirigido por Oliva Acosta para el Ayuntamiento de Chiclana que está compuesto por un documental y un disco con 26 canciones interpretadas por las protagonistas. La iniciativa pretende preservar la memoria y el legado de 18 mujeres de más de 80 años de la localidad.

Asimismo, los premios y distinciones obtenidas por la cineasta gaditana son los siguientes: 
- 2005: Premio del Festival de Nueva York al mejor reportaje de investigación: Infancia Rota (Documentos TV).

- 2011: Premio Meridiana: Las constituyentes.

- 2011: Festival de Málaga. Mención de Honor por Las constituyentes.

- 2011: Festival de Sevilla. Mención Especial por Las constituyentes.

- 2011: Festival de Huesca. Sección Oficial por Las constituyentes.

- 2011: MiradasDoc. Sección Oficial. Fuera de concurso por Las constituyentes.

- 2011: Festival Alcances de Cádiz. Sección Oficial - Fuera de Concurso por Las constituyentes.

- 2011: Festival de Cine Español de Nantes (Francia). Sección Oficial por Las constituyentes.

- 2012: V Premio Participando Creamos Igualdad en la categoría Arte y Cultura, otorgado por el Consejo de las Mujeres del municipio de Madrid.

- 2012: 8 candidaturas de Las constituyentes a los Premios Goya 2012. Son las siguientes: película, dirección, guion original, dirección de producción, dirección de fotografía, montaje, sonido, película documental.

- 2014: Bandera de Andalucía en Cádiz.

- 2014: Premio Clara Campoamor Andalucía.

\section{Discusión}

El papel de las mujeres en la industria audiovisual española ha adquirido relevancia en las últimas décadas (Cascajosa Virino y Martínez Pérez, 2016); no obstante, aún dista de configurarse como un sector igualitario, ya que los hombres prevalecen en la profesión, salvo en los casos de responsabilidades tradicionalmente feminizadas. Por otra parte, son una minoría las mujeres que ocupan puestos de decisión como directoras, productoras o guionistas (Bernárdez-Rodal y Padilla-Castillo, 2018; Eurimages, 2020; MIA, 2020).

Esta desigualdad se debe no solo a los obstáculos propios de una industria con gran temporalidad y en la que ha prevalecido históricamente la perspectiva masculina, sino a las barreras de género a las que se enfrentan las profesionales. Tal y como indican trabajos previos (Núñez Domínguez, 2010b; Núñez Domínguez 2014; Ocón Aburto y Núñez Domínguez, 2020), las mujeres afrontan una exigencia continua de demostrar su valía y una importante dificultad para compaginar su vida profesional con las responsabilidades familiares. La situación se agrava cuando se trata de hacer audiovisual en zonas alejadas de los grandes centros de producción, puesto que también deben superarse los escollos derivados de un tejido productivo de menor solidez y en el que las mujeres disponen aún de un espacio más reducido (Guarinos, 1999a; Silva, 2015). 
Incorporar el talento femenino al sector resulta clave, no solo para construir una industria más igualitaria, sino para fomentar el avance social y combatir los estereotipos de género.

Múltiples investigaciones (Ballesteros, 2011; Bartolomé, 2017; Lozano, 2020) demuestran que los medios de comunicación perpetúan los estereotipos de género porque de forma mayoritaria asumen una perspectiva masculina a la hora de construir sus discursos, dejando de lado la visión de las mujeres (Prado, 1998; Weitz, 2016; Nuñez Domínguez y Vera Balanza, 2020).

Por todo ello, esta investigación aboga por reivindicar el papel de las profesionales de esta industria, donde existen ejemplos muy interesantes de mujeres que han desarrollado una trayectoria relevante como la de la propia Acosta.

\section{Conclusiones}

La trayectoria de Oliva Acosta viene marcada, desde incluso antes de dedicarse al audiovisual, por sus experiencias personales y profesionales. Su trabajo periodístico como responsable de comunicación en Naciones Unidas $y$, específicamente, el desarrollado durante la Conferencia de Pekín y los años que le siguieron hicieron que sus creaciones posteriores tuvieran un marcado acento social y una indeleble perspectiva de género.

Pero esa actividad, que transcurrió durante la década de los 90 entre Nueva York y Bruselas en contacto estrecho con oenegés y colectivos de mujeres, la hizo igualmente consciente de la importancia de establecer redes de contacto, aprovechando además el potencial que le ofrecían tanto las nuevas tecnologías de la información como el propio medio audiovisual. Esto no se refleja únicamente en sus documentales, sino también en la actividad asociativa que mantiene actualmente como vocal de la AAMMA.

Su obra, además, está caracterizada por un tercer elemento: la oralidad como vehículo comunicativo para recuperar y salvaguardar los testimonios y la memoria olvidada de las mujeres, ya fuesen anónimas o figuras públicas, sepultados por la historiografía escrita por los hombres. Este recurso se ha utilizado ampliamente en la mayoría de su legado cinematográfico: Reyita, Las constituyentes, 25 años abriendo camino, Las memorables, etc.

Pionera también entre las mujeres propietarias de una productora y en establecerse profesionalmente en Andalucía, su filmografía posee un último rasgo distintivo: el interés por los temas periféricos -igualmente ocultos por la atracción que ejercen los grandes focos mediáticos-, que es considerado por la autora como una oportunidad 
para narrar historias alternativas alejadas de la centralidad informativa tanto nacional como internacional.

La faceta profesional a la que ha llegado más recientemente, la de formadora, ha sido empleada por Acosta con una doble intencionalidad: en primer lugar, para continuar desplegando su activismo feminista con la realización de actividades en pro de la igualdad y el empoderamiento de las mujeres en los centros educativos; $y$, por otro lado, para animar a las jóvenes a ocupar puestos de trabajo en el sector audiovisual, en especial aquellos tradicionalmente masculinizados.

Se alcanzan así los objetivos de este trabajo al determinar que la gaditana ha jugado un papel relevante como documentalista en la industria audiovisual española de las últimas décadas. Además, se ha profundizado en la evolución de su carrera desde sus inicios, identificado su filmografía y puesto de manifiesto su enfoque y estilo como creadora.

La presente investigación también pone el foco en la importancia de reclamar la figura de la mujer creadora y visibilizar a mujeres profesionales como referentes en la comunicación en general y en el audiovisual en particular. Esta necesidad se hace extensiva no solo a las pioneras que abrieron camino durante la mayor parte del siglo $X X$, sino también a figuras más recientes que resultan inspiradoras por constituir un modelo para las profesionales que ya ejercen y las que lo harán en el futuro.

El objeto de estudio que aquí se aborda constituye un tema de gran interés que puede continuar su desarrollo mediante futuras líneas de investigación que profundicen en otras figuras relevantes de la industria audiovisual española, tanto en puestos de decisión como en perfiles técnicos donde la presencia de mujeres es aún muy reducida.

\section{Referencias bibliográficas}

AAMMA (2021): Oliva Acosta. Asociación Andaluza de Mujeres de los Medios Audiovisuales. Disponible en Internet (17-2-2021): http://aammaudiovisual.com/portfolio/oliva-acosta/

ANDALUCíA. Ley 1/2004, de 17 de diciembre, de creación del Consejo Audiovisual de Andalucía. Boletín Oficial del Estado, 14 de enero de 2005, núm. 12, pp. 1529 a 1533.

ANDALUCÍA. Ley 10/2018, de 9 de octubre, audiovisual de Andalucía. Boletín Oficial del Estado, 7 de noviembre de 2018, núm. 269, pp. 108238 a 108290. 
ARRANZ, F. (coord.) (2008): Mujeres y hombres en el cine español. Una investigación empírica, Madrid, Instituto de la Mujer

BALLESTEROS GARCÍA, R. M. (2011): "Escritoras en la gran pantalla. La legión de la decencia vs. la fábrica de sueños" en Aposta. Revista de Ciencias Sociales, no 50, pp. 1-30. https://dialnet.unirioja.es/servlet/articulo?codigo=3858880

BAÑóN CASTELLÓN, L. (2021): “Comunicar i marcar la diferència. Testimonis de joves periodistes valencianes, por A. Carratalá, D. Palau, R. Miralles i J.L. Gómez Mompart, eds.: Por Lola Bañón Castellón”, en RIHC. Revista Internacional de Historia de la Comunicación, (15), pp. 273-276. https://doi.org/10.12795/RiHC.2020.i15.19

BARRERA VELASCO, P. (2019): “Pionerismo femenino en la cinematografía española: el papel de las mujeres en la configuración de la modernidad fílmica", en MORENO LAGO, E. M. Pioneras, escritoras y creadoras del siglo XX 16, Ediciones Universidad de Salamanca, pp. 141-154.

BARTOLOMÉ PINA, C. (2017): “La mujer cineasta, ¿un hecho diferencial...?”, en MARCILLAS PIQUERAS. I. (ed.): Dones i identitats: Realitats i imaginaris, Alicante: Servicio de publicaciones de la Universidad de Alicante, pp. 175-185.

BERNÁRDEZ-RODAL, A. Y PADILLA-CASTILLO, G. (2018): “Mujeres cineastas y mujeres representadas en el cine comercial español (2001-2016)", en Revista Latina de Comunicación Social, 73, pp. 1247-1266. http://dx.doi.org/10.4185/RLCS-2018$\underline{1305}$

CINES ZOCO MAJADAHONDA (2014). Oliva Acosta (Directora de "Las Constituyentes") en Cines Zoco Majadahonda. Disponible en Internet (12-3-2021): https://www.youtube.com/watch?v=Zb2JaxPvcLQ

DEL RÍO, O. Y VELÁZQUEZ, T. (2005): “Planificación de la investigación en Comunicación: fases del proceso". En BERGANZA, R. Y RUIZ SAN ROMÁN, J. A., Investigar en comunicación, McGraw Hill, pp. 43-76.

CABRERA, A., FLORES, T. M., Y MATA, M. J. (2012): "O feminino como" intruso" na política: uma análise do contexto histórico e da representação fotojornalística das deputadas portuguesas no" parlamento paritário" e nas discussões da lei da paridade", en Revista Media e Jornalismo: política no feminino, vol. 11, no 21, pp. 77-127. http://hdl.handle.net/10400.21/4145

CASCAJOSA VIRINO, C. (2015): “Mujeres pioneras y creación televisiva en España: una revisión crítica", en NÚÑEZ DOMÍNGUEZ, T., VERA BALANZA, M.T. Y DÍAZ JIMÉNEZ, R.M. (Eds.) Transversalidad de género en el audiovisual andaluz, Universidad Internacional de

Andalucía,

pp.

91-103. 
https://riuma.uma.es/xmlui/bitstream/handle/10630/10771/transversalidad-degenero-en-el-av-andaluz.pdf? sequence $=1 \#$ page $=91$

CASCAJOSA VIRINO, C. Y MARTÍNEZ PÉREZ, N. (2016): “Del cine a la televisión: hacia una genealogía de las mujeres guionistas en España", en FEMERIS: Revista Multidisciplinar de Estudios de Género, vol. 1, № 1/2, pp. 25-34. http://dx.doi.org/10.20318/femeris.2016.3225

CRUZADO, M. A. (2006): "Grietas en el techo de celuloide. Directoras del siglo XXI", en ARRIAGA, M. (Coord). Mujeres, espacio y poder, Sevilla, Arcibel Editores, pp. 153173.

ESPAÑA. Ley 7/2010, de 31 de marzo, General de la Comunicación Audiovisual. Boletín Oficial del Estado, 1 de abril de 2010, núm. 79, pp. 30157 a 30209.

ESPAÑA. Ley Orgánica 3/2007, de 22 de marzo, para la igualdad efectiva de mujeres y hombres. Boletín Oficial del Estado, 23 de marzo de 2007, núm 71, pp.12611 a 12645.

ESPAÑA. Real Decreto 1090/2020, de 9 de diciembre, por el que se modifica el Real Decreto 1084/2015, de 4 de diciembre, por el que se desarrolla la Ley 55/2007, de 28 de diciembre, del Cine. Boletín Oficial del Estado, 10 de diciembre de 2020, núm. 322, pp. 112849 a 112859.

EURIMAgeS (ed.) (2020): Gender Parity Statistics - Annual Data Collection and Publication Template 2018, Eurimages, Council of Europe. https://rm.coe.int/gender-statistics-annual-data-collection-2018-finalmarch/16809d43e2

FUNDACIÓN AUDIOVISUAL DE ANDALUCÍA (2009a): “La Ley de Igualdad, un reto para el audiovisual" en Meridiam, no $50, \quad$ p. 42. http://www.juntadeandalucia.es/institutodelamujer/catalogo/doc/MERIDIAM/M ERIDIAM 50.pdf

FUNDACIÓN AUDIOVISUAL DE ANDALUCÍA (2009b): Análisis de las oportunidades de empleo de la Industria Audiovisual en Andalucía. Caracterización, tendencias y perspectivas, Dirección General de Empleabilidad e Intermediación Laboral, Consejería de Empleo, Junta de Andalucía. https://www.juntadeandalucia.es/export/drupaljda/1 1978 analisis oportunida des de empleo de la industria audiovisual en andalucia.pdf

GAITÁN MOYA, J. A. Y PIÑUEL RAIGADA, J. L. (1998): Técnicas de investigación en comunicación social. Elaboración y registro de datos, Síntesis. 
GORJÓN, R. (n.d.): "Oliva Acosta: «La política está en lo personal y en lo cotidiano»", Cine y comedia, http://cineycomedia.com/entrevista-oliva-acosta/

GUARINOS, V. (1999a): "La mujer andaluza tras la cámara: un presente esperanzador", en GUARINOS, V. (Ed). Alicia en Andalucía: la mujer andaluza como personaje cinematográfico, la mujer andaluza tras la cámara, Filmoteca de Andalucía, pp. 131-135.

- (1999b): "Pepa Álvarez. Del escondite a la firme presencia”, en GUARINOS, V. (Ed). Alicia en Andalucía: la mujer andaluza como personaje cinematográfico, la mujer andaluza tras la cámara, Filmoteca de Andalucía, pp. 141-150.

HIGUERAS-RUIZ, M. J. (2019): "Showrunners y personajes femeninos en las series de ficción de la industria televisiva norteamericana: Sharp Objects (Marti Noxon, HBO: 2018) y Killing Eve (Phoebe Waller-Bridge, BBC America: 2018)", en: Admira: Análisis de Medios, Imágenes y Relatos Audiovisuales, vol. 7, no 2, pp. 85-106. https://hdl.handle.net/11441/100972

IMDb (2021): Oliva Acosta, Internet Movie Database. Disponible en Internet (17-22021): https://www.imdb.com/name/nm4791185/

LOZANO, S. (2020): “Mirada al pasado: Estereotipos y arquetipos de género en series históricas españolas (2011-2018)", en Comunicación y medios, vol. 29, № 41, pp. 67-79. https://dx.doi.org/10.5354/0719-1529.2020.54276

MARTín, A. P (2013, 31 de enero). "Las constituyentes nos enseñan la pasión por el servicio al país", El País, Disponible en Internet (17-2-2021): https://elpais.com/elpais/2013/01/31/mujeres/1359633309 135963.html

MARTínEZ-COlLAdo MARTínEZ, A. Y NAVARRETE TUDELA, A. (2011): “Mujeres e industria audiovisual hoy: Involución, experimentación y nuevos modelos narrativos", en TESI, vol. 12, no 1, pp. 8-23. http://hdl.handle.net/10366/100620

MIA (2020). Informe MIA 2020: Mujeres en la industria de la animación, MIA. Disponible en Internet (17-2-2021): https://animacionesmia.com/wpcontent/uploads/2020/10/INFORME MIA 2020.pdf

NÚÑEZ DOMíNGUEZ, T. (2010a): "Mujeres directoras de cine: un reto, una esperanza", en Pixel-Bit. Revista de Medios y Educación, no 37, pp. 121-133. https://www.redalyc.org/articulo.oa?id=36815118010

- (2010b): "De lo visible y lo invisible: acceder y promocionar en la empresa audiovisual", en Revista Digital de la Fundación Audiovisual de Andalucía (1-2) https://idus.us.es/bitstream/handle/11441/23752/delovisible.pdf?sequence=1

- (2014): “Barreras en el acceso y la promoción profesional de las mujeres: argumentos para el cambio en el sector audiovisual", en CARO, F., J., Y NOGALES, 
A. I. Emprender en femenino en la Comunicación, Cuadernos Artesanos de Comunicación, pp. 71-95. http://hdl.handle.net/11441/30615

NÚÑEZ DOMÍNGUEZ, T. Y VERA BALANZA, M. T. (2020): “Directoras de cine argentinas y españolas. Una década re-creando imaginarios", en Cuadernos.info, (46), pp. 96128. https://doi.org/10.7764/cdi.46.1459

OCÓN ABURTO, M. Y NÚÑEZ DOMÍNGUEZ, T. (2020): “Gestión del tiempo de mujeres y hombres en la producción cinematográfica andaluza", en Mediaciones Sociales, noㅡ 19, pp. 1-11. http://dx.doi.org/10.5209/meso.66582

PRADO, I. (1998): "Al otro lado de la cámara propia: Mujeres directoras del cine español", en Confluencia, 13, no 2, 76-83. http://www.jstor.org/stable/27922622

PROMMER, E. Y LOIST, S. (2015): Wer dreht deutsche Kinofilme? Gender report: 20092013, Universität Rostock, Institut für Medienforschung.

RUFFINELLI, J. (2014): “Ellas lo hacen mejor (Un cine nuevo: el de mujeres)", en Cinémas d'Amérique latine, no 22, pp. 80-89. https://doi.org/10.4000/cinelatino.785

SARDÁ, J. (2012, 14 diciembre): "Oliva Acosta", en El Cultural. Disponible en Internet (17-2-2021): https://elcultural.com/Oliva-Acosta

SILVA, M. (2015): Women in focus. Situación de las mujeres en el Audiovisual Andaluz, Fundación Audiovisual de Andalucía. Recuperado de https://archivo.amecopress.net/-2020/pdf/women in focus.pdf

SMITH, S., CHOUEITI, M., Y PIEPER, K. (2014): “Gender Bias Without Borders. An investigation of female characters in popular films across 11 countries", en Media, Diversity \& Social Change Initiative USC Annenberg. Disponible en Internet (27-22021): https://seejane.org/wp-content/uploads/gender-bias-without-bordersfull-report.pdf

SWEDISH FILM INSTITUTE (ed.) (2021): WHICH WHO MEN? Gender Equality Report 2019/2020. Swedish Film Institute. Disponible en Internet (4-2-2021): https://rm.coe.int/gender-equality-report-19-20swedish-filminstitute/1680a11fe4

TORRES-MARTíN, J. L. Y CASTRO-MARTíNEZ, A. (2021): "Prácticas comunicativas periféricas en los medios de comunicación en España. El caso de La Poderío", en Revista de la Asociación Española de Investigación de la Comunicación, 8 (15), pp. 170-198. https://doi.org/10.24137/raeic.8.15.8

UNIVERSIDAD INTERNACIONAL DE ANDALUCÍA (2015). Women in focus. Sin las mujeres no es cine. Disponible en Internet (9-3-2021): https://vimeo.com/158077706 
VERA BALANZA, M. T. Y NÚÑEZ DOMÍNGUEZ, T. (2020, 28 de septiembre): "Las directoras del cine español, del blanco y negro al color", en The Conversation. Disponible en Internet (17-2-2021): https://theconversation.com/las-directorasdel-cine-espanol-del-blanco-y-negro-al-color146992\#: :text=As\%C3\%AD\%2C\%20Cristina\%20Andreu\%2C\%20Marta\%20Arriba s,Azucena\%20Rodr\%C3\%ADguez\%20Pomeda\%2C\%20Mireia\%20Ros\%2C

WEITZ, R. (2016): “Feminism, Post-feminism, and Young Women's Reactions to Lena Dunham's Girls", en Gender issues, no 33, pp. 218-234. https://doi.org/10.1007/s12147-015-9149-y

WIMMER, R. D. Y DOMINICK, J. R. (1996): La investigación científica de los medios de comunicación: una introducción a sus métodos. Barcelona: Bosch.

WOMEN IN FILM LOS ÁNGELES (ed.) (2020): Women in Film annual report gender parity: the view from here 2019. Women in Film Los Ángeles. Disponible en Internet (172-2021): $\quad$ http://womeninfilm.org/wp-content/uploads/2020/05/WIF AR 325 FINAL hi-res.pdf

ZURIAN, F.A. (coord.) (2015): Construyendo una mirada propia: mujeres directoras en el cine español. De los orígenes al año 2000. Madrid, Editorial Síntesis.

\section{Filmografía}

Beijing +5. Acciones, no palabras (1995). Oliva Acosta. EEUU: rodado en la ONU en Nueva York y emitido en el programa La Noche Temática (TVE).

Somos lo que comemos (2001). Mar Mas y Oliva Acosta (dirección), Martha Zhein y Oliva Acosta (guion). España: Kaisut Media S.L. para Documentos TV (TVE).

Infancia rota (2005): José Pedro Estepa (dirección), Oliva Acosta y Elena Ortega (guion y producción). España: Creación Multimedia S.A. para Documentos TV (TVE).

Mujer quiere a mujer. Madres invisibles. (2004): José Pedro Estepa (realización), Oliva Acosta (guion). España: Creación Multimedia S.A. para Documentos TV (TVE).

Hombres (2006): José Pedro Estepa (dirección), Oliva Acosta y Jordi Bohigas (investigación). España: Creación Multimedia S.A. para Documentos TV (TVE).

Mi vida por 1000 euros (2008): María Martín (dirección), Oliva Acosta (guion). España: Documentos TV (TVE).

Reyita (2007): Elena Ortega (dirección). Oliva Acosta, Elena Ortega, Rocío Santillana (guion). España: CPI. 
Las constituyentes (2011): Oliva Acosta (dirección, guion y producción). España: Olivavá Producciones.

25 años abriendo caminos (2014): Oliva Acosta y Ana Rosa Diego (dirección y guion). España: Instituto Andaluz de la Mujer.

La murga, una ópera popular (2014): David Baute (dirección y guion), David Baute, Yvonne Ruocco y Oliva Acosta (producción). España-Uruguay: Tinglado Films.

Las memorables (2019): Oliva Acosta (dirección y guion). España: Ayuntamiento de Chiclana y Olivavá Producciones. 